\title{
Hypothalamic Kisspeptin Expression in Hyperandrogenic Female Rats and Aging Rats
}

\author{
Kinuyo Iwata, Yuyu Kunimura and Hitoshi Ozawa \\ Department of Anatomy and Neurobiology, Graduate School of Medicine, Nippon Medical School, Bunkyo-ku, Tokyo 113- \\ 8602, Japan
}

Received May 22, 2019; accepted August 5, 2019; published online September 26, 2019

\begin{abstract}
Hypothalamic kisspeptin neurons stimulate gonadotropin-releasing hormone $(\mathrm{GnRH})$ and luteinizing hormone (LH) release. Kisspeptin neurons in the anteroventral periventricular nucleus (AVPV) of rats induce an LH surge for ovulation, and those in the arcuate nucleus (ARC) regulate pulsatile LH secretion for follicle development and spermatogenesis. Dysfunction of kisspeptin neurons thus reduces the reproductive function. This review focuses on the effect of androgen or aging on kisspeptin expression in rats. Although androgen directly suppresses ARC kisspeptin neurons in female rats, the AVPV kisspeptin neurons are hardly affected. In rats, plasma LH concentrations decrease in both sexes with aging, and ARC kisspeptin expression also decreases in old rats compared with young rats. In addition, kisspeptin neurons may be associated with hyperprolactinemia in old female rats because they are known to release prolactin through hypothalamic tuberoinfundibular dopaminergic (TIDA) neurons. Hypothalamic kisspeptin neurons are thus the main regulator to secrete LH, and inhibition of kisspeptin expression leads to various kinds of reproductive dysfunction.
\end{abstract}

Key words: Kiss1, androgen, neurokinin B, dynorphin, dopaminergic neuron

\section{Hypothalamic Kisspeptin Neurons on Reproduction}

Hypothalamic kisspeptin neurons play a pivotal role in regulating the reproductive function by stimulating the release of gonadotropin-releasing hormone $(\mathrm{GnRH})$ and luteinizing hormone (LH) in mammals. G protein-coupled receptor 54 (GPR54) is a kisspeptin receptor encoded by the Kiss 1 gene, and mutations in GPR54 cause hypogonadotropic hypogonadism in humans and mice [7, 12, 39]. In rodents, hypothalamic kisspeptin neurons are primarily localized in the anteroventral periventricular nucleus (AVPV) and arcuate nucleus (ARC). AVPV kisspeptin neurons are considered to be a target of estrogen-

Correspondence to: Kinuyo Iwata, Department of Anatomy and Neurobiology, Graduate School of Medicine, Nippon Medical School, 1-1-5 Sendagi, Bunkyo-ku, Tokyo 113-8602, Japan.

E-mail: kiwata0309@nms.ac.jp positive feedback to induce preovulatory $\mathrm{GnRH} / \mathrm{LH}$ surges. However, ARC kisspeptin neurons are negatively regulated by sex steroids on GnRH/LH secretion. ARC kisspeptin neurons that coexpress neurokinin $\mathrm{B}$ (NKB) and dynorphin (Dyn) are known as KNDy neurons. They are thought to be associated with the generation of pulsatile $\mathrm{GnRH} / \mathrm{LH}$ secretions $[27,45]$. NKB and Dyn are also negatively controlled by estrogen [22]. Our previous immunoelectron microscopic study showed that three neuropeptides in KNDy neurons are separately contained in discrete neurosecretory vesicles of cell bodies and axons (Fig. 1) [30], suggesting that these neuropeptides, kisspeptin, NKB and Dyn are separately synthesized in KNDy neurons.

\section{Effect of Androgen on Kisspeptin Expression and LH Release in Female Rats}

Hyperandrogenemia is characterized by elevated androgens in the plasma and is one of the criteria for 

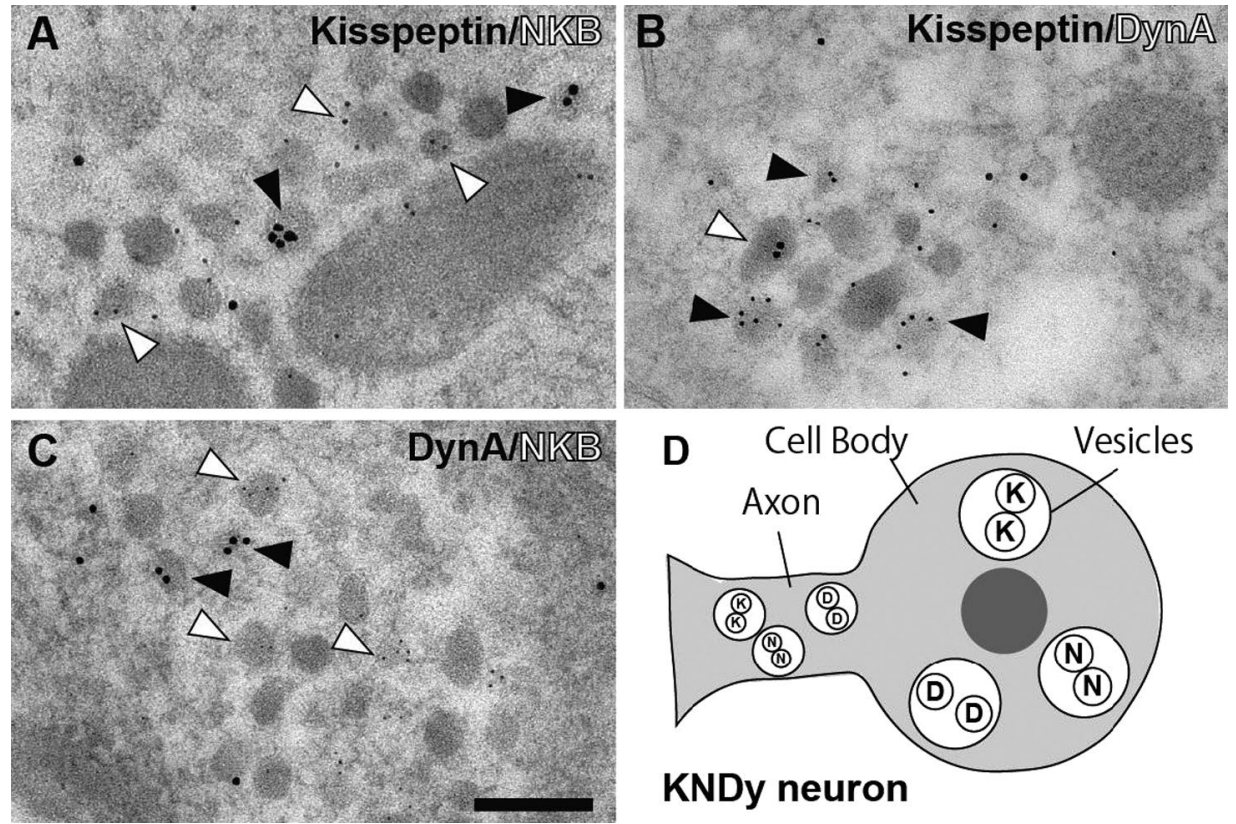

Fig. 1. Double immunoelectron micrographs of the axons of KNDy neurons in the ARC of female rats. (A) Solid arrowheads show kisspeptinimmunoreactive (ir) vesicles. Open arrowheads, neurokinin B (NKB)-ir vesicles. (B) Solid arrowheads, kisspeptin-ir vesicles. Open arrowheads, dynorphin A (DynA)-ir vesicles. (C) Solid arrowheads, DynA-ir vesicles. Open arrowheads, NKB-ir vesicles. Bar = $200 \mathrm{~nm}$. (D) Schematic illustration of the KNDy neuron. Kisspeptin (K), NKB (N) and DynA (D) were observed in discrete neurosecretory vesicles in the axons and the cell bodies. For details, refer to [30].
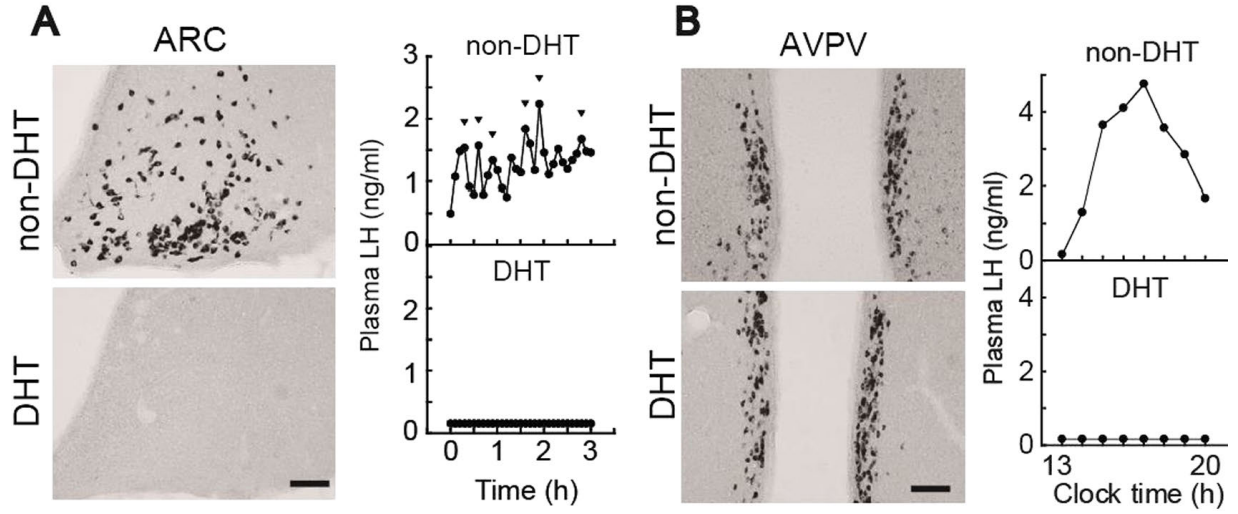

Fig. 2. (A) Kiss 1 mRNA-expressing cells in the ARC and LH pulses in chronically DHT-treated female rats. Female rats were implanted subcutaneously with 90-day continuous-release DHT pellets at weaning dates. Non-DHT animals were intact then. DHT and non-DHT animals were ovariectomized 2 weeks before the blood and brain were collected. Kiss 1 cells were detected by in situ hybridization. Bar $=100 \mu \mathrm{m}$. (B) Kiss 1 cells in the AVPV and estradiol (E2)-induced LH surge. DHT and non-DHT rats were ovariectomized and implanted with tubes containing a high concentration of E2. Bar = $100 \mu \mathrm{m}$. For details, refer to [21].

the diagnosis of polycystic ovary syndrome [8]. Women with hyperandrogenemia have ovulatory abnormalities, which may lead to infertility [13]. Manneras et al. showed that female rats continuously administered $5 \alpha$ dihydrotestosterone (DHT) from prepuberty to an adult age exhibited irregular estrus cycles [29]. Additionally, pulsatile LH secretion was suppressed in DHT-treated female rats (Fig. 2A) [21]. Thus, androgen affects the female reproductive function. Kisspeptin neurons in the ARC are considered to be a pulse generator of $\mathrm{GnRH} / \mathrm{LH}$ for follicle development in females. The number of Kiss 1 -expressing cells in the ARC was significantly lower in DHT rats (Fig. 2A) [21], and hypothalamic kisspeptin immunoreactivity was reduced in female rats chronically exposed to DHT [4]. These results indicated that androgen suppresses kisspeptin expression in the ARC, resulting in the suppression of pulsatile LH secretion in female rats. These results coincide with previous studies on male mice which found that Kiss 1 expression in the ARC was reduced by DHT treatment in castrated mice [40].

The LH surge in females is induced by high levels of estrogen and triggers ovulation. Kisspeptin neurons in the 


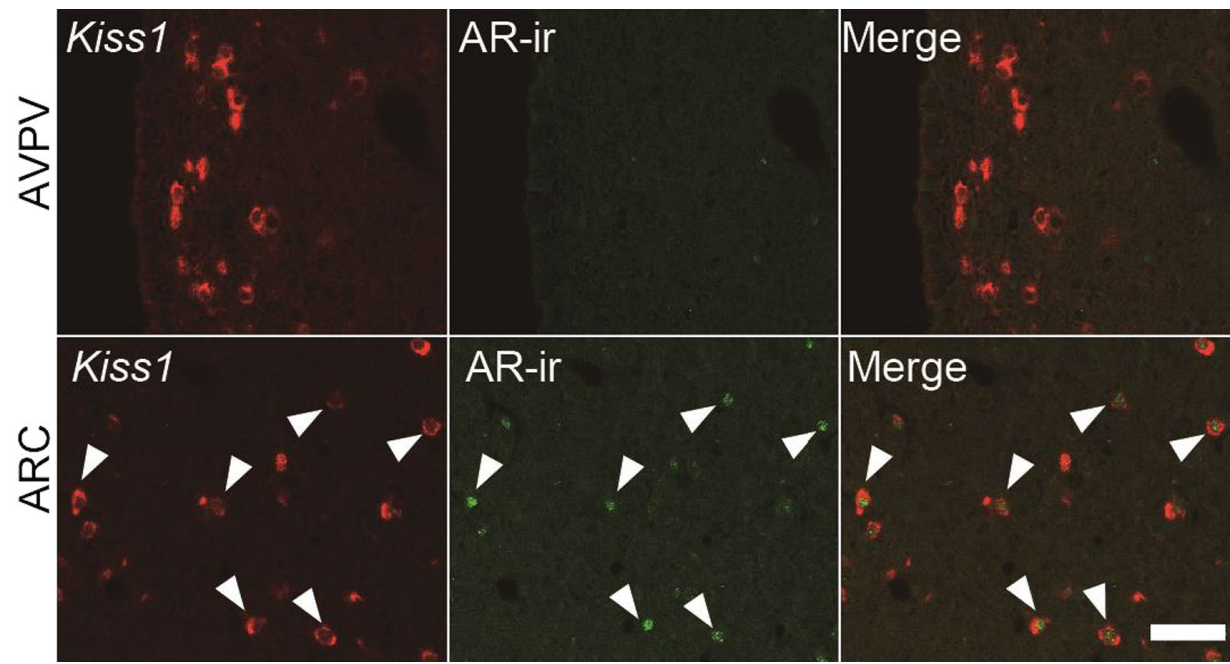

Fig. 3. Expression of androgen receptor (AR) on kisspeptin neurons in the AVPV and ARC of normal adult female rats. Kiss1 mRNA-expressing cells, red; AR-immunoreactive (ir) cells, green. Arrowheads indicate coexpression of Kiss 1 and AR. Bar $=50 \mu \mathrm{m}$. For details, refer to [21].

AVPV respond to high levels of estrogen and induce an LH surge. However, no LH surge was detectable in DHT female rats in the presence of high estradiol (E2) (Fig. 2B). Despite that, the number of AVPV Kiss1-expressing cells did not vary significantly between non-DHT female rats and DHT rats (Fig. 2B) [21]. In contrast to the ARC, kisspeptin neurons in the AVPV were not affected by androgen in female rats.

Kisspeptin neurons in the ARC express androgen receptor (AR) in male mice and ewes $[28,40]$ and in the AVPV of male mice [5]. Our study demonstrated that about $63 \%$ of kisspeptin neurons in the ARC expressed AR in female rats, whereas kisspeptin neurons hardly expressed AR in the AVPV (about 1.5\%, [21]) (Fig. 3). Excessive androgen levels in female animals thus suppress kisspeptin expression in the ARC through AR, resulting in subsequent suppression of LH pulses. Conversely, kisspeptin neurons in the AVPV are not considered to be directly affected by androgen (Fig. 3). The suppression of high E2-induced LH surges in DHT rats may be caused by disruption in both the hypothalamus and the pituitary, because administration of GnRH agonist or kisspeptin did not induce LH release in the plasma of DHT rats [21]. Hence, hyperandrogenemia in women may adversely affect ARC kisspeptin neurons, resulting in anovulation and menstrual irregularities.

\section{KNDy Neurons in Aging Rats}

The secretion of gonadotropins is elevated in postmenopausal women because the negative feedback effects of ovarian sex steroids are lacking after the onset of the menopause. However, some studies have shown that the frequency or amplitude of pulsatile LH secretion decreases in older postmenopausal women compared with younger ones $[16,26,36,37]$. These studies show that LH secretion gradually decreases as aging progresses postmenopause. In older men, testosterone levels decreases with aging [17]; however, some studies of older men did not show this reduction in testosterone levels $[1,46]$. Additionally, LH concentrations increased modestly and slowly with aging in men [46]. Mean LH secretion decreases with aging in rats, and in old female rats, the amplitude of the LH pulse is also lower [10]. The frequency and amplitude of LH pulses decreased in old male mice compared with young ones [6]. Our study showed that total LH concentrations over three hours decreased in both sexes with aging (Fig. 4A) [25] These results suggest that $\mathrm{LH}$ secretion in rodents also reduces with aging.

Regarding KNDy neurons, the number of Kiss 1expressing cells in the ARC was lower in old female rats compared with young ones (Fig. 4B). The mRNA expression of Tac3 and Pdyn genes in the ARC, which are respectively encoding NKB and Dyn, also decreased in old female rats. In male rats, the total number of Kiss1-, Tac3and Dyn-expressing cells in the ARC was lower in old rats compared with young rats (Fig. 4B). The numbers of kisspeptin-, NKB-, and dynorphin A-immunoreactive (ir) cells were also lower in old rats of both sexes [25]. These results show that a reduction in KNDy expression may be a cause of reproductive dysfunction in old animals.

\section{Interaction between Kisspeptin Neurons and Hypothalamic Tuberoinfundibular Dopaminergic (TIDA) Neurons in Aging Rats}

The tuberoinfundibular dopaminergic (TIDA) neurons are known to regulate prolactin secretion. The cell bodies of TIDA neurons are found in the dorsomedial ARC and project to the median eminence. Dopamine secreted from TIDA neurons is released into the pituitary portal blood and inhibits prolactin release in lactotrophs $[11,14]$. TIDA neu- 
A

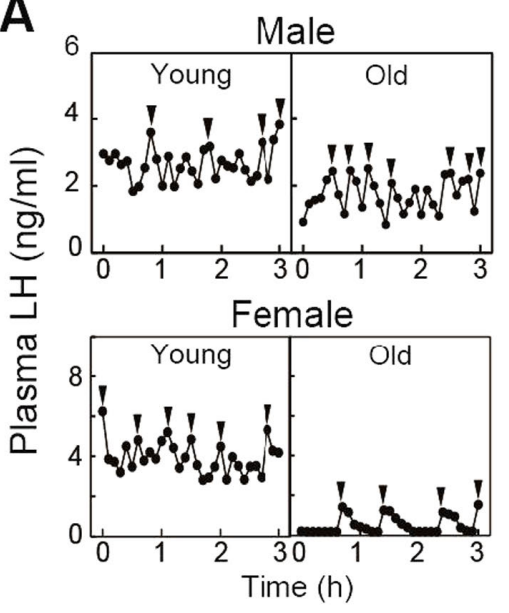

B
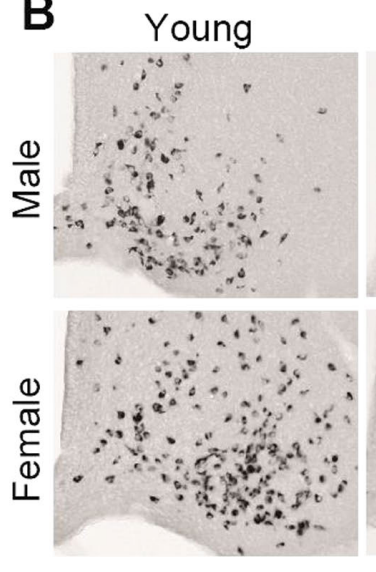

Old

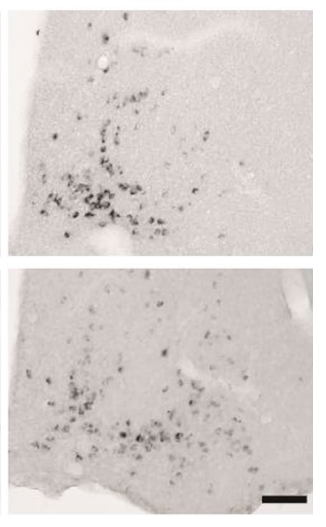

Fig. 4. LH pulses (A) and Kiss1 mRNA expressions in the ARC (B) of young and old rats. Animals were gonadectomized 2 weeks before the blood and brain were collected. Young rats, 2-3 months (M) of age; old rats, 24-26 M. Kiss 1-expressing cells were detected by in situ hybridization. Bar = 100 $\mu \mathrm{m}$. For details, refer to [25].
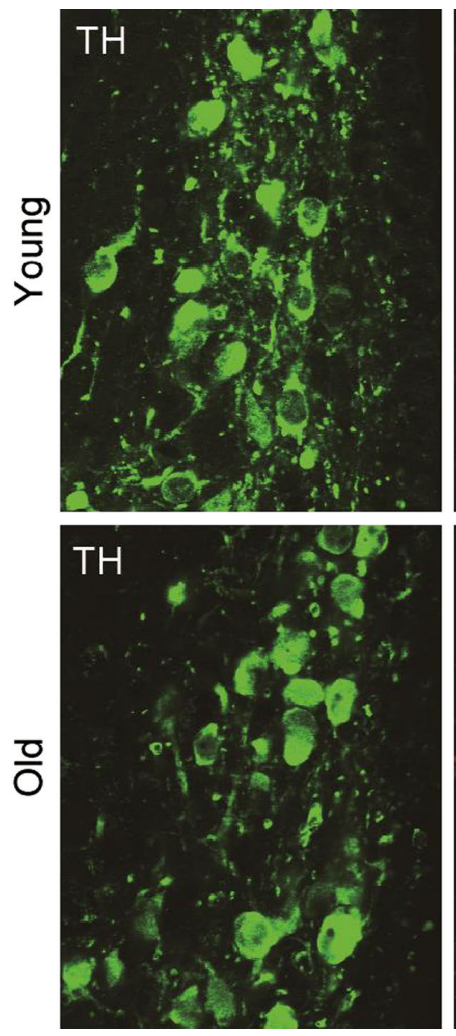
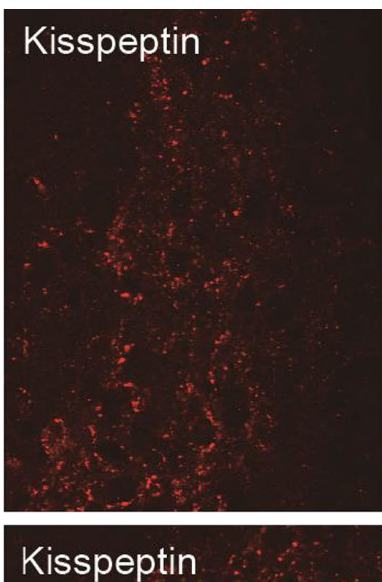
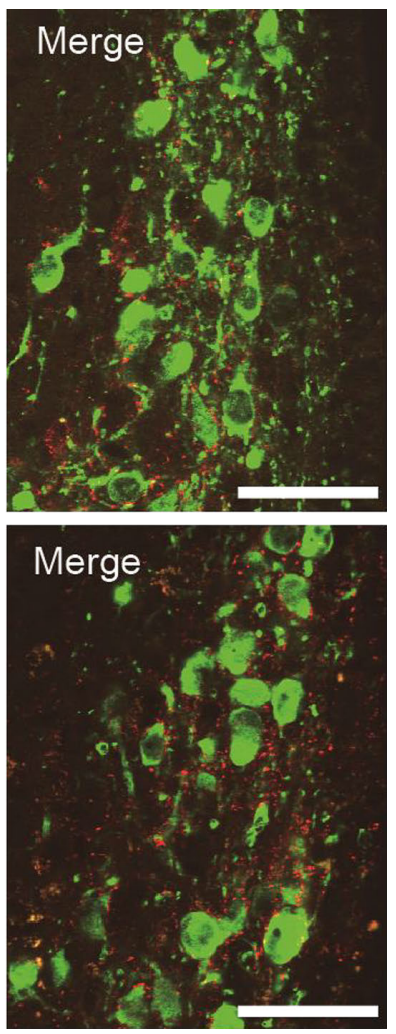

Fig. 5. Double immunostaining for tyrosine hydroxylase (TH, green) and kisspeptin (red) in the dorsomedial arcuate nucleus (ARC) of rats. Upper panels show images from the ARC of young rats during the diestrus stage. Lower panels show images from old rats $(24$ months of age). Bars $=50 \mu m$. For details, refer to [20].

rons are inhibited by serotonin, noradrenaline and estrogen, resulting in increased prolactin secretion [11]. Kisspeptin also induces prolactin release through inhibition of TIDA neurons in the presence of estrogen [35, 42], and its fibers are in physical contact with TIDA neurons [38, 42]. Biotinlabeled kisspeptin bound to the cell bodies of TIDA neurons [19]. In addition, kisspeptin neurons express prolactin receptors [24] and are suppressed by prolactin [3]. Thus, kisspeptin and prolactin levels are regulated in coordination with each other.

Serum prolactin levels are known to increase with aging in female [20, 41] and male rats [15]. Tyrosine hydroxylase (TH) is an enzyme of catecholamine synthesis and identifies dopaminergic neurons. There was no differ- 


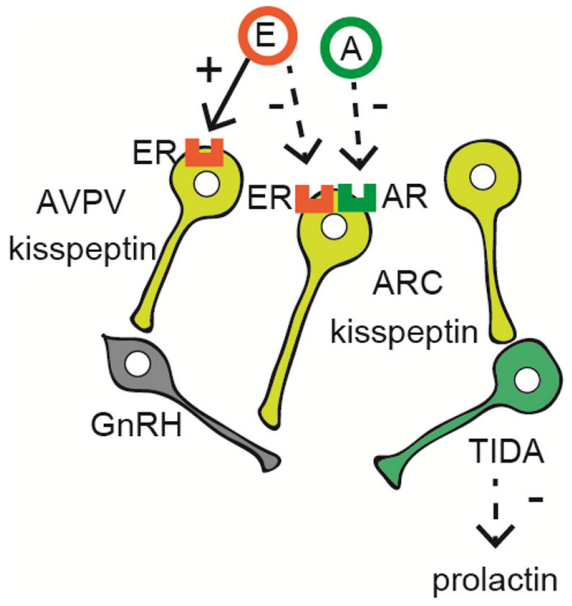

Fig. 6. Kisspeptin neurons stimulate GnRH/LH releases. Estrogen (E) positively affects AVPV kisspeptin neurons through estrogen receptors (ER). Estrogen (E) and androgen (A) negatively affect ARC kisspeptin neurons through each receptor. Kisspeptin also induces prolactin release through inhibition of hypothalamic tuberoinfundibular dopaminergic (TIDA) neurons.

ence in the number of $\mathrm{TH}$-ir cell bodies in the ARC or in the levels of TH mRNA expression in the hypothalamus between young and old female rats [20, 32, 34]. However, dopamine levels in the pituitary portal blood of old rats were lower than in young rats of both sexes [32], and TH activity in the medial hypothalamus was reduced in old female rats compared with young ones [34]. Hyperprolactinemia in old rats may therefore be induced by a decrease in $\mathrm{TH}$ activity followed by a decrease in dopamine secretion rather than by a decrease in the number of $\mathrm{TH}$-expressing cells.

Kisspeptin neurons are in contact with TIDA neurons. Kisspeptin-ir fibers were found in the dorsomedial ARC of both young and old female rats, but the number of TH-ir cells in contact with kisspeptin-ir fibers did not differ between young and old female rats (Fig. 5) [20]. Conversely, kisspeptin expression in the ARC was lower in old rats compared with young rats $[20,25]$; thus the kisspeptinir fibers in old rats may be detected by an accumulation of kisspeptin in the terminal fibers due to suppression of kisspeptin secretion. Variations in kisspeptin expression and/or secretion may affect prolactin secretion via TIDA neurons in old rats. At least, contacts between kisspeptin neurons and TIDA neurons appear to be maintained during aging. Kisspeptin receptor was expressed in only $15 \%$ of TIDA neurons [18], and a current study has shown that kisspeptin neurons rather than TIDA neurons regulate prolactin secretion through dopaminergic neurons in the hypothalamic periventricular nucleus [2]. Kisspeptin activates neuropeptides FF receptors [9], so further studies are needed to investigate whether kisspeptin stimulates prolactin release through other receptors, and dopaminergic neurons are in contact with kisspeptin neurons in other areas of old rats.

\section{Conclusion}

Figure 6 shows the summary of this review. Kisspeptin neurons in the hypothalamus are one of main regulators for reproduction, and thus their dysfunction will lead to an attenuated reproductive function. Hyperandrogenemia and aging are considered to adversely affect kisspeptin neurons in the ARC. Other factors, including leptin $[31,33]$, thyroid hormone [44] and corticotropin-releasing hormone [23, 43], are also involved in the expression of kisspeptin neurons. It would appear that hypothalamic kisspeptin neurons sense information that is used to control the reproductive function.

\section{Conflicts of Interest}

There are no conflicts of interest.

\section{Acknowledgments}

This work was supported by Grants-in-Aid from JSPS (24790240, 15K18979 to K. I., 22590230, 26460323, $18 \mathrm{~K} 06860$ to H. O.) and the MEXT-supported Program for Strategic Research Foundation at Private Universities. This paper is a summary of the contents presented as a Young Research Encouragement Prize Lecture at the Japanese Society of Histochemistry and Cytochemistry in 2018.

\section{References}

1. Abbara, A., Narayanaswamy, S., Izzi-Engbeaya, C., Comninos, A. N., Clarke, S. A., Malik, Z., Papadopoulou, D., Clobentz, A., Sarang, Z., Bassett, P., Jayasena, C. N. and Dhillo, W. S. (2018) Hypothalamic Response to Kisspeptin-54 and Pituitary Response to Gonadotropin-Releasing Hormone Are Preserved in Healthy Older Men. Neuroendocrinology 106; 401-410.

2. Aquino, N. S. S., Kokay, I. C., Perez, C. T., Ladyman, S. R., Henriques, P. C., Silva, J. F., Broberger, C., Grattan, D. R. and Szawka, R. E. (2019) Kisspeptin Stimulation of Prolactin Secretion Requires Kiss1 Receptor but Not in Tuberoinfundibular Dopaminergic Neurons. Endocrinology 160; 522-533.

3. Araujo-Lopes, R., Crampton, J. R., Aquino, N. S., Miranda, R. M., Kokay, I. C., Reis, A. M., Franci, C. R., Grattan, D. R. and Szawka, R. E. (2014) Prolactin regulates kisspeptin neurons in the arcuate nucleus to suppress LH secretion in female rats. Endocrinology 155; 1010-1020.

4. Brown, R. E., Wilkinson, D. A., Imran, S. A., Caraty, A. and Wilkinson, M. (2012) Hypothalamic kiss1 mRNA and kisspeptin immunoreactivity are reduced in a rat model of polycystic ovary syndrome (PCOS). Brain Res. 1467; 1-9.

5. Clarkson, J., Shamas, S., Mallinson, S. and Herbison, A. E. (2012) Gonadal steroid induction of kisspeptin peptide expression in the rostral periventricular area of the third ventricle during postnatal development in the male mouse. $J$. Neuroendocrinol. 24; 907-915.

6. Coquelin, A. and Desjardins, C. (1982) Luteinizing hormone and testosterone secretion in young and old male mice. Am. J. Physiol. 243; E257-263.

7. de Roux, N., Genin, E., Carel, J. C., Matsuda, F., Chaussain, J. L. and Milgrom, E. (2003) Hypogonadotropic hypogonadism due to loss of function of the KiSS1-derived peptide receptor GPR54. 
Proc. Natl. Acad. Sci. U S A 100; 10972-10976.

8. Ehrmann, D. A. (2005) Polycystic ovary syndrome. N. Engl. J. Med. 352; 1223-1236.

9. Elhabazi, K., Humbert, J. P., Bertin, I., Schmitt, M., Bihel, F., Bourguignon, J. J., Bucher, B., Becker, J. A., Sorg, T., Meziane, H., Petit-Demouliere, B., Ilien, B. and Simonin, F. (2013) Endogenous mammalian RF-amide peptides, including PrRP, kisspeptin and 26RFa, modulate nociception and morphine analgesia via NPFF receptors. Neuropharmacology 75; 164-171.

10. Estes, K. S., Simpkins, J. W. and Chen, C. L. (1980) Alteration in pulsatile release of LH in aging female rats. Proc. Soc. Exp. Biol. Med. 163; 384-387.

11. Freeman, M. E., Kanyicska, B., Lerant, A. and Nagy, G. (2000) Prolactin: structure, function, and regulation of secretion. Physiol. Rev. 80; 1523-1631.

12. Funes, S., Hedrick, J. A., Vassileva, G., Markowitz, L., Abbondanzo, S., Golovko, A., Yang, S., Monsma, F. J. and Gustafson, E. L. (2003) The KiSS-1 receptor GPR54 is essential for the development of the murine reproductive system. Biochem. Biophys. Res. Commun. 312; 1357-1363.

13. Goodman, N. F., Bledsoe, M. B., Cobin, R. H., Futterweit, W., Goldzieher, J. W., Petak, S. M., Smith, K. D., Steinberger, E. and American Association of Clinical Endocrinologists Hyperandrogenic Disorders Task Force (2001) American Association of Clinical Endocrinologists medical guidelines for the clinical practice for the diagnosis and treatment of hyperandrogenic disorders. Endocr. Pract. 7; 120-134.

14. Grattan, D. R. (2015) 60 Years of Neuroendocrinology: The hypothalamo-prolactin axis. J. Endocrinol. 226; T101-122.

15. Gudelsky, G. A., Nansel, D. D. and Porter, J. C. (1981) Dopaminergic control of prolactin secretion in the aging male rat. Brain Res. 204; 446-450.

16. Hall, J. E., Lavoie, H. B., Marsh, E. E. and Martin, K. A. (2000) Decrease in gonadotropin-releasing hormone $(\mathrm{GnRH})$ pulse frequency with aging in postmenopausal women. J. Clin. Endocrinol. Metab. 85; 1794-1800.

17. Harman, S. M., Metter, E. J., Tobin, J. D., Pearson, J. and Blackman, M. R. (2001) Longitudinal effects of aging on serum total and free testosterone levels in healthy men. Baltimore Longitudinal Study of Aging. J. Clin. Endocrinol. Metab. 86; 724-731.

18. Higo, S., Iijima, N. and Ozawa, H. (2017) Characterisation of Kiss1r (Gpr54)-Expressing Neurones in the Arcuate Nucleus of the Female Rat Hypothalamus. J. Neuroendocrinol. 29. doi: 10.1111/jne. 12452

19. Iijima, N., Takumi, K., Matsumoto, K. and Ozawa, H. (2015) Visualization of Kisspeptin Binding to Rat Hypothalamic Neurons. Acta Histochem. Cytochem. 48; 179-184.

20. Iwata, K., Ikehara, M., Kunimura, Y. and Ozawa, H. (2016) Interactions between Kisspeptin Neurons and Hypothalamic Tuberoinfundibular Dopaminergic Neurons in Aged Female Rats. Acta Histochem. Cytochem. 49; 191-196.

21. Iwata, K., Kunimura, Y., Matsumoto, K. and Ozawa, H. (2017) Effect of androgen on Kiss1 expression and luteinizing hormone release in female rats. J. Endocrinol. 233; 281-292.

22. Kanaya, M., Iwata, K. and Ozawa, H. (2017) Distinct dynorphin expression patterns with low- and high-dose estrogen treatment in the arcuate nucleus of female rats. Biol. Reprod. 97; 709-718.

23. Kinsey-Jones, J. S., Li, X. F., Knox, A. M., Wilkinson, E. S., Zhu, X. L., Chaudhary, A. A., Milligan, S. R., Lightman, S. L. and O'Byrne, K. T. (2009) Down-regulation of hypothalamic kisspeptin and its receptor, Kiss1r, mRNA expression is associated with stress-induced suppression of luteinising hormone secretion in the female rat. J. Neuroendocrinol. $21 ; 20$ 29 .
24. Kokay, I. C., Petersen, S. L. and Grattan, D. R. (2011) Identification of prolactin-sensitive GABA and kisspeptin neurons in regions of the rat hypothalamus involved in the control of fertility. Endocrinology 152; 526-535.

25. Kunimura, Y., Iwata, K., Ishigami, A. and Ozawa, H. (2017) Age-related alterations in hypothalamic kisspeptin, neurokinin B, and dynorphin neurons and in pulsatile LH release in female and male rats. Neurobiol. Aging 50; 30-38.

26. Lambalk, C. B., de Boer, L., Schoute, E., Popp-Snyders, C. and Schoemaker, J. (1997) Post-menopausal and chronological age have divergent effects on pituitary and hypothalamic function in episodic gonadotrophin secretion. Clin. Endocrinol. (Oxf.) 46; 439-443.

27. Lehman, M. N., Coolen, L. M. and Goodman, R. L. (2010) Minireview: kisspeptin/neurokinin B/dynorphin (KNDy) cells of the arcuate nucleus: a central node in the control of gonadotropin-releasing hormone secretion. Endocrinology 151; 3479-3489.

28. Lehman, M. N., Merkley, C. M., Coolen, L. M. and Goodman, R. L. (2010) Anatomy of the kisspeptin neural network in mammals. Brain Res. 1364; 90-102.

29. Manneras, L., Cajander, S., Holmang, A., Seleskovic, Z., Lystig, T., Lonn, M. and Stener-Victorin, E. (2007) A new rat model exhibiting both ovarian and metabolic characteristics of polycystic ovary syndrome. Endocrinology 148; 3781-3791.

30. Murakawa, H., Iwata, K., Takeshita, T. and Ozawa, H. (2016) Immunoelectron microscopic observation of the subcellular localization of kisspeptin, neurokinin $\mathrm{B}$ and dynorphin $\mathrm{A}$ in KNDy neurons in the arcuate nucleus of the female rat. Neurosci. Lett. 612; 161-166.

31. Nakao, K., Iwata, K., Takeshita, T. and Ozawa, H. (2018) Expression of hypothalamic kisspeptin, neurokinin B, and dynorphin A neurons attenuates in female Zucker fatty rats. Neurosci. Lett. 665; 135-139.

32. Porter, J. C., Aguila-Mansilla, N., Ramin, S. M. and Kedzierski, W. (1994) Secretion by hypothalamic dopaminergic neurons of the aged brain. Neurobiol. Aging 15; 535-539.

33. Quennell, J. H., Howell, C. S., Roa, J., Augustine, R. A., Grattan, D. R. and Anderson, G. M. (2011) Leptin deficiency and dietinduced obesity reduce hypothalamic kisspeptin expression in mice. Endocrinology 152; 1541-1550.

34. Reymond, M. J., Arita, J., Dudley, C. A., Moss, R. L. and Porter, J. C. (1984) Dopaminergic neurons in the mediobasal hypothalamus of old rats: evidence for decreased affinity of tyrosine hydroxylase for substrate and cofactor. Brain Res. 304; 215-223.

35. Ribeiro, A. B., Leite, C. M., Kalil, B., Franci, C. R., AnselmoFranci, J. A. and Szawka, R. E. (2015) Kisspeptin regulates tuberoinfundibular dopaminergic neurones and prolactin secretion in an oestradiol-dependent manner in male and female rats. J. Neuroendocrinol. 27; 88-99.

36. Rossmanith, W. G. (1995) Gonadotropin secretion during aging in women: review article. Exp. Gerontol. 30; 369-381.

37. Santoro, N., Banwell, T., Tortoriello, D., Lieman, H., Adel, T. and Skurnick, J. (1998) Effects of aging and gonadal failure on the hypothalamic-pituitary axis in women. Am. J. Obstet. Gynecol. 178; 732-741.

38. Sawai, N., Iijima, N., Takumi, K., Matsumoto, K. and Ozawa, H. (2012) Immunofluorescent histochemical and ultrastructural studies on the innervation of kisspeptin/neurokinin B neurons to tuberoinfundibular dopaminergic neurons in the arcuate nucleus of rats. Neurosci. Res. 74; 10-16.

39. Seminara, S. B., Messager, S., Chatzidaki, E. E., Thresher, R. R., Acierno, J. S. Jr., Shagoury, J. K., Bo-Abbas, Y., Kuohung, W., Schwinof, K. M., Hendrick, A. G., Zahn, D., Dixon, J., Kaiser, 
U. B., Slaugenhaupt, S. A., Gusella, J. F., O'Rahilly, S., Carlton, M. B., Crowley, W. F. Jr., Aparicio, S. A. and Colledge, W. H. (2003) The GPR54 gene as a regulator of puberty. N. Engl. J. Med. 349; 1614-1627.

40. Smith, J. T., Dungan, H. M., Stoll, E. A., Gottsch, M. L., Braun, R. E., Eacker, S. M., Clifton, D. K. and Steiner, R. A. (2005) Differential regulation of KiSS-1 mRNA expression by sex steroids in the brain of the male mouse. Endocrinology 146; 2976-2984.

41. Steger, R. W. (1981) Age related changes in the control of prolactin secretion in the female rat. Neurobiol. Aging 2; 119 123.

42. Szawka, R. E., Ribeiro, A. B., Leite, C. M., Helena, C. V., Franci, C. R., Anderson, G. M., Hoffman, G. E. and AnselmoFranci, J. A. (2010) Kisspeptin regulates prolactin release through hypothalamic dopaminergic neurons. Endocrinology $151 ; 3247-3257$.

43. Takumi, K., Iijima, N., Higo, S. and Ozawa, H. (2012) Immunohistochemical analysis of the colocalization of corticotropin-releasing hormone receptor and glucocorticoid receptor in kisspeptin neurons in the hypothalamus of female rats. Neurosci. Lett. 531; 40-45.

44. Tomori, Y., Takumi, K., Iijima, N., Takai, S. and Ozawa, H. (2017) Kisspeptin expression is decreased in the arcuate nucleus of hypothyroid female rats with irregular estrus cycles. Neurosci. Res. 117; 35-41.

45. Uenoyama, Y., Pheng, V., Tsukamura, H. and Maeda, K. I. (2016) The roles of kisspeptin revisited: inside and outside the hypothalamus. J. Reprod. Dev. 62; 537-545.

46. Xia, F., Wang, N., Han, B., Li, Q., Chen, Y., Zhu, C., Chen, Y., Pu, X., Cang, Z., Zhu, C., Lu, M., Meng, Y., Guo, H., Chen, C., Lin, D., Zheng, J., Kuang, L., Tu, W., Li, B., Hu, L., Shen, Z. and Lu, Y. (2017) Hypothalamic-Pituitary-Gonadal Axis in Aging Men and Women: Increasing Total Testosterone in Aging Men. Neuroendocrinology 104; 291-301.

This is an open access article distributed under the Creative Commons Attribution License, which permits unrestricted use, distribution, and reproduction in any medium, provided the original work is properly cited. 